\title{
NÚCLEOS DE DESERTIFICAÇÃO DO NORDESTE BRASILEIRO: SUSCETIBILIDADE E DINÂMICA PLUVIOMÉTRICA
}

\author{
Ivamauro Ailton de Sousa Silva ${ }^{(a)}$ \\ (a) Doutorando em Geografia, Instituto de Geociências, Universidade Federal do Rio Grande do Sul - UFRGS, \\ ivamauro@hotmail.com
}

Eixo: Climatologia em diferentes níveis escalares: mudanças e variabilidades

\begin{abstract}
Resumo
No espaço geográfico brasileiro, a região nordeste apresenta, os exemplos mais significativos de desertificação. A finalidade desta pesquisa é discutir a utilização do índice de aridez como parâmetro mundial, empregado para definir as áreas suscetíveis a desertificação (ASD) e ainda caracterizar a dinâmica pluviométrica dos núcleos de desertificação no Brasil: Gilbués no Piauí, Irauçuba-Ceará, Cabrobó-Pernambuco e Seridó no Rio Grande do Norte, enfatizando suas características acerca do regime e distribuição pluvial das áreas em questão. Para isso, a pesquisa foi constituída por revisão bibliográfica, pela elaboração de mapas temáticos, construídos por meio de bases cartográficas do Ministério do Meio Ambiente e também através da coleta e análise de dados meteorológicos, utilizando apenas dados pluviométricos. Como resultados, o artigo elucida que as condições climáticas (aridez, seca prolongada, reduzidos volumes pluviométricos e escassez hídrica) são indicadores do processo de desertificação. Os núcleos de desertificação, apresentam variações na distribuição pluviométrica, revelando, por exemplo, períodos semelhantes e diferenças marcantes no regime e ritmo pluvial. Entre os quartos núcleos de desertificação, o núcleo de Gilbués, é o único localizado em clima tropical e apresenta quantidade e distribuição pluviométrica, que se diferencia dos demais núcleos, portanto, possui discrepância climática em relação aos demais municípios.
\end{abstract}

Palavras-chave: Desertificação; Nordeste brasileiro; Suscetibilidade; Dinâmica Pluviométrica.

\section{Introdução}

No Brasil, os primeiros trabalhos que apresentam o conceito de desertificação como a degradação das terras produtivas no semiárido, foram conduzidos na região nordeste brasileira, por Vasconcelos Sobrinho (1971). Sem dúvida alguma, deve-se a este pesquisador o mérito do pioneirismo nos estudos de desertificação no Brasil.

Durante muito tempo, se associou a desertificação com um processo de formação de deserto. Vasconcelos Sobrinho (2002), por exemplo, afirmava que o semiárido brasileiro é um deserto em potencial, um deserto em formação, em função da ruptura do equilíbrio instável desse ambiente, ruptura esta provocada pelas atividades antrópicas. 
Oliveira-Galvão (2001) afirma que a desertificação, não constitui a formação ou ampliação de desertos. Conforme a autora

os desertos constituem ecossistemas, que se encontram em equilíbrio dinâmico, apresentando complexas interações físicas e químicas, variadas formas biológicas, naturalmente adaptadas ao meio, e cujas populações humanas encontram-se historicamente ajustadas às suas condições. A desertificação, atua direcionando o ambiente a condições de paisagem tipo desértica, determinando perda dos solos, escassez dos recursos hídricos, retrogressão biótica, improdutividade agrícola e abandono das terras (GALVÃO, 2001, p. 1).

Existem diversos autores, que discutem o conceito de "desertificação". Para Vasconcelos Sobrinho (1978), a desertificação é um processo de fragilidade dos ecossistemas das terras secas em geral, decorrentes da pressão excessiva das populações humanas, perdem a produtividade e a capacidade de se recuperarem.

Ab'Saber (1977, p.1), define desertificação como "processos parciais, pontuais ou areolares, suficientemente radicais para designar degradações irreversíveis da paisagem e dos tecidos ecológicos naturais". Segundo ainda este autor, as feições de degradação pontuais no território brasileiro são de fácil reconhecimento, principalmente nas paisagens sertanejas do nordeste brasileiro, incluídas na categoria de verdadeiros geótopos áridos.

Ab’Saber (1977, op. cit.), caracterizou as áreas suscetíveis à desertificação, de acordo com a predisposição da estrutura geoecológica, determinada, principalmente pelas deficiências hídricas sazonais, que em alguns setores associam-se às atividades humanas.

Para Nimer (1980, p. 614), desertificação é "a crescente degradação ambiental expressa pelo ressecamento e perda da capacidade de produção dos solos. Esse ressecamento crescente do meio natural pode ser uma decorrência da mudança do clima regional e ou do uso inadequado dos solos pelo homem.

Conti (1995), define desertificação como processo e dinâmica, estando, frequentemente, associado a períodos secos bastante longos, que apresentam alta variabilidade climática, constituindo regiões situadas em clima árido.

Para Suertegaray (2001) o processo de desertificação é reservado para expressar a degradação do solo, vegetação e água em condições climáticas específicas, bem como períodos secos prolongados, baixos índices pluviométricos e presença de aridez.

A Convenção das Nações Unidas para o Combate à Desertificação (UNCCD), conceitua a desertificação como o processo de degradação das terras das regiões áridas, semiáridas e subúmidas secas, resultantes de fatores diversos tais como as variações climáticas e derivações antropogênicas (BRASIL, 1999). 
De acordo com Oliveira-Galvão (2001) a ocorrência da desertificação é considerada restrita aos ambientes áridos, semi-áridos e subúmidos secos, que naturalmente apresentam fragilidade ambiental e limitadas condições de autocontrole ou autorecuperação, frente à instalação de processos transformadores.

Para determinar a suscetibilidade que determinada região tem ao processo de desertificação, a UNCCD considera as zonas áridas, semiáridas e subúmidas secas todas as áreas com exceção das polares e das subpolares, com Índice de Aridez (IA) entre 0,05 e 0,65.

Atualmente, o índice de aridez serve como parâmetro mundial, e é estimado pelo quociente entre a quantidade de precipitação média anual (P) e a perda máxima possível de água por meio da evapotranspiração potencial total anual (ETP). Os tipos de clima com suas respectivas amplitudes de aridez são apresentados no quadro 1.

Quadro 1 - tipos de clima segundo a amplitude de aridez e a escala de suscetibilidade à desertificação

\begin{tabular}{|c|c|c|}
\hline Zonas climáticas & Amplitude do Índice de Aridez (IA) & Escala de suscetibilidade à desertificação \\
\hline Hiper-árido & $<0,005$ & Nenhuma \\
\hline Árido & $\mathbf{0 , 0 5}-\mathbf{0 , 2 0}$ & Muito alta \\
\hline Semiárido & $\mathbf{0 , 2 1}-\mathbf{0 , 5 0}$ & Alta \\
\hline Subumido Seco & $\mathbf{0 , 5 1 - 0 , 6 5}$ & Moderada \\
\hline Subumido e Úmido & $>0,65$ & Nenhuma \\
\hline
\end{tabular}

Fonte: UNEP, 2007; MMA, 2004

Conforme o quadro 1, observa-se que as áreas susceptíveis à desertificação no Brasil estão localizadas na região Nordeste, com predomínio de climas semiáridos e subúmidos secos, com IA variando entre 0,21 a 0,65. Estas regiões têm em comum o fato de serem caracterizadas pela ausência, escassez, quantidade limitada e, ainda, pela distribuição irregular das precipitações pluviométricas, associadas a elevadas taxas de evaporação. Assim, o índice de aridez é uma ferramenta para os estudos e as classificações de áreas susceptíveis à desertificação do ponto de vista climático.

Desta forma, este artigo tem como finalidade apresentar uma discussão teórica sobre o processo de desertificação no âmbito dos estudos climáticos. A pesquisa também aborda a dinâmica pluviométrica dos núcleos de desertificação do nordeste brasileiro, no qual, pretende-se compreender e caracterizar o quadro pluvial destas áreas, na tentativa de verificar o comportamento e as variações do regime e no ritmo das chuvas. 
XVII Simpósio Brasileiro

de Geografia Física Aplicada

I Congresso Nacional

de Geografia Física
OS DESAFIOS DA GEOGRAFIA FÍSICA NA FRONTEIRA DO CONHECIMENTO

Instituto de Geociências - Unicamp

Campinas - SP

28 de Junho à 02 de Julho de 2017

\section{$2 \quad$ Materiais e métodos}

A pesquisa foi realizada em três etapas distintas e complementares. Primeiramente foi realizado um estudo teórico processo de desertificação no território brasileiro. Em seguida, elaborarou-se o mapeamento das áreas susceptíveis à desertificação e núcleos de desertificação do Nordeste Brasileiro. Os mapas das áreas suscetíveis à desertificação (ASD) e os respectivos núcleos de desertificação do Brasil, foram gerados utilizando-se bases de dados do Ministério do Meio Ambiente (MMA), e através do emprego de ferramentas disponíveis no Sistemas de Informações Geográficas (SIG), tais como ArcGIS.

Em seguida, foi feito o levantamento de informações referentes as características pluviométricas a partir da literatura científica e dados obtidos e disponíveis na Superintendência do Desenvolvimento do Nordeste (SUDENE) e pelo Instituto Nacional de Meteorologia (INMET). Essa etapa, possibilitou a elaboração dos pluviogramas (gráficos de precipitação), que equivale numa representação cartográfica, que mostram a variação porcentual das precipitações mensais/diárias em relação à precipitação total de cada ano/mês, indicando o mês mais seco e o mês mais úmido e revelando, por meio de um histograma, os totais pluviométricos anuais e sua espacialização a partir das normais climatológicas da SUDENE (19611980) e do INMET (1980-1990). Por fim, foi possível fazer o tratamento, a interpretação, a análise e a exploração dos dados obtidos nas etapas anteriores.

\section{Os núcleos de desertificação no NEB: localização, condições climáticas e suscetibilidades}

Vasconcelos Sobrinho (1978), ao estudar as áreas suscetíveis à desertificação (ASD), selecionou empiricamente, áreas pilotos, onde existiam intensos processos de degradação de solo e da cobertura vegetal no Nordeste brasileiro, condicionada por "um equilíbrio ecológico instável decorrente do regime pluviométrico de baixo índice de precipitações e extrema irregularidade, dos solos rasos com limitada capacidade de retenção de água, amplo fotoperiodismo e ventos secos e quentes com forte poder de desidratação" (VASCONCELOS SOBRINHO, p. 41, 1971).

O referido autor relacionou os indicadores a serem considerados na desertificação (físicos, biológicos, sociais, uso da terra e processos sociais) e estabeleceu, ainda, o conceito de áreas-parâmetro como recobertas de vegetação primitiva, contíguas às que ocorrem desertificações (áreas-piloto), permitindo comparar a evolução deste fenômeno.

As áreas selecionadas por Vasconcelos Sobrinho (1978), foram caracterizadas como de alto risco à desertificação e foram designadas de Núcleos de Desertificação, descritas como áreas em que a degradação da cobertura vegetal e do solo alcançou uma condição de irreversibilidade. Ainda o referido 


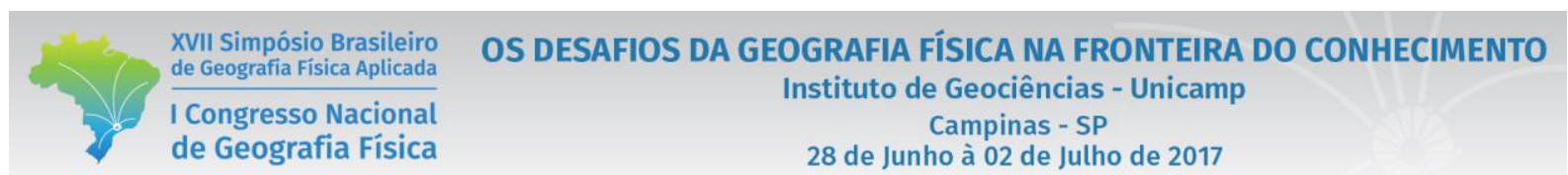

autor, indicou os núcleos existentes do nordeste brasileiro, e aponta os espaços geográficos mais problemáticos e potenciais à desertificação: Gilbués-PI; Irauçuba-CE; Região do Seridó Norteriograndense-RN; e Cabrobró-PE, reconhecidas e caracterizadas até hoje pela literatura (Figura 1).

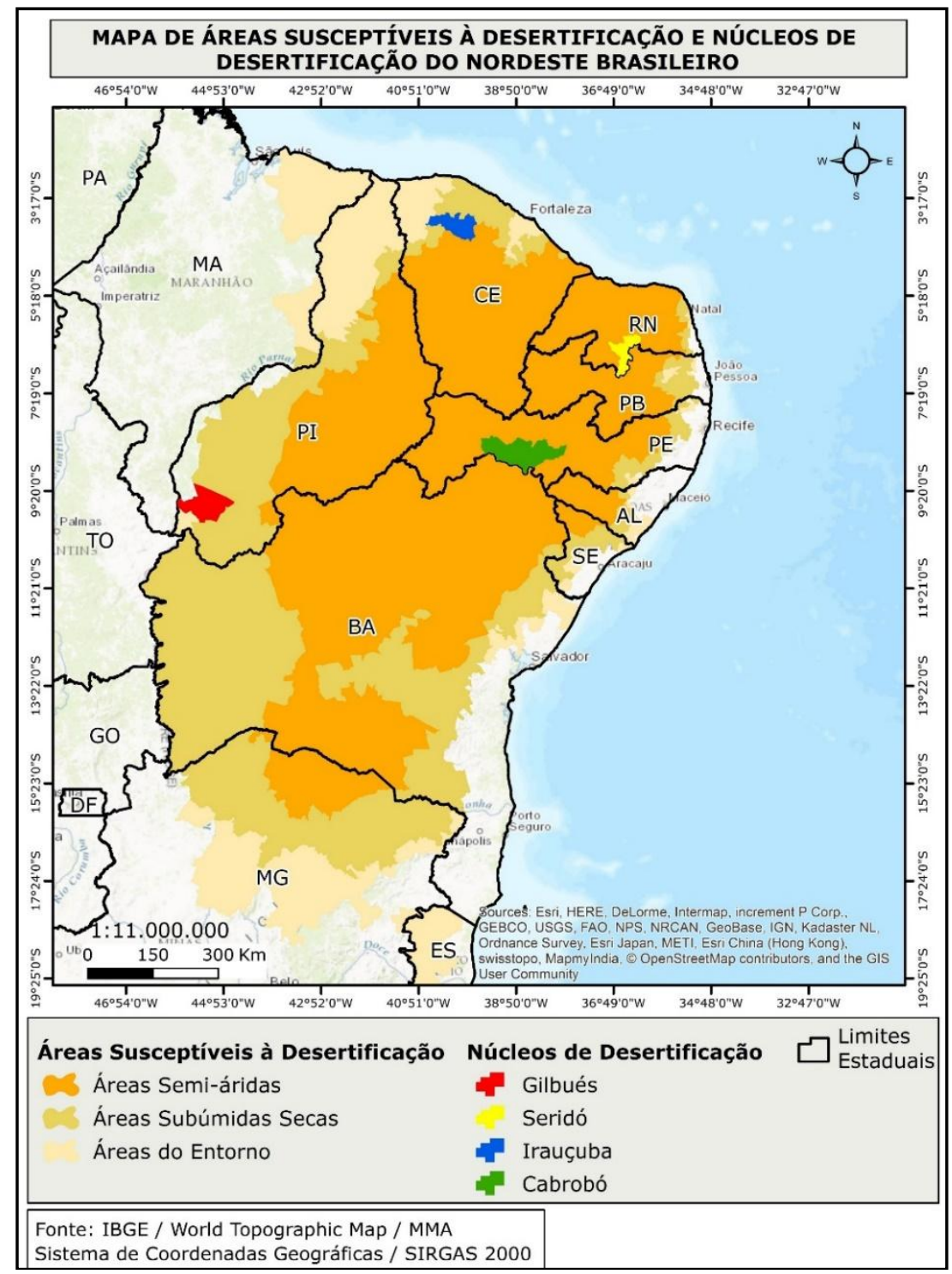

Figura 1 - Mapa de áreas susceptíveis à desertificação e núcleos de desertificação do nordeste brasileiro

Todos os núcleos de desertificação estão localizados na região nordeste brasileira, em clima semiárido, com exceção do núcleo de Gilbués, que predomina clima subúmido. Conforme a revisão teórica, os núcleos de Irauçuba-CE, Cabrobó-PE, Seridó-RN apresentam totais pluviométricos inferiores a 800 mm/ano, extensos períodos de estiagem e escassez de recursos hídricos (BRASIL, 2004). O núcleo de Gilbués, conforme Silva (2014) apresenta pluviosidade em torno de 1.200 mm/ano, ausência de aridez e de períodos prolongados de seca (Quadro 2). 


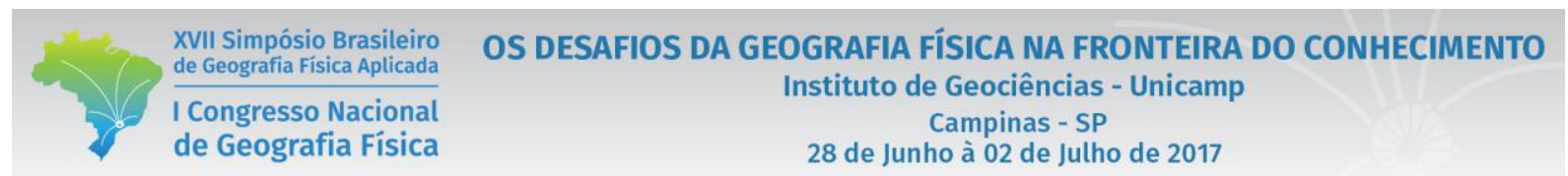

Quadro 2 - características climáticas dos núcleos de desertificação do NEB

\begin{tabular}{|c|c|c|c|}
\hline Núcleo & $\begin{array}{c}\text { Tipo climático } \\
\text { Köppen-Geiger }\end{array}$ & Pluviosidade média anual & Temperatura média anual \\
\hline Gilbués & Subúmido & $1.200 \mathrm{~mm}$ & $\mathbf{2 5}^{\circ} \mathrm{C}$ \\
\hline Iraçubua & Semiárido & $\mathbf{6 2 9} \mathrm{mm}$ & $\mathbf{2 6 , 3}^{\circ} \mathrm{C}$ \\
\hline Seridó & Semiárido & $\mathbf{4 3 2} \mathrm{mm}$ & $\mathbf{2 2 , 2}^{\circ} \mathrm{C}$ \\
\hline Cabrobó & Semiárido & $\mathbf{5 4 1} \mathrm{mm}$ & $\mathbf{2 5 , 5}^{\circ} \mathrm{C}$ \\
\hline
\end{tabular}

Fonte: INMET (1961-1990); BRASIL (2004); SILVA (2014)

Em termos regionais, a dinâmica pluviométrica dos núcleos de desertificação, se caracteriza por uma ampla diferenciação, relevada, principalmente, pelo regime e distribuição espacial das precipitações, apresentando clima semiárido e subúmido. As características pluviais dos núcleos de Gilbués, Iraúçuba, Cabrobó e Seridó, estão representadas na figura 2.

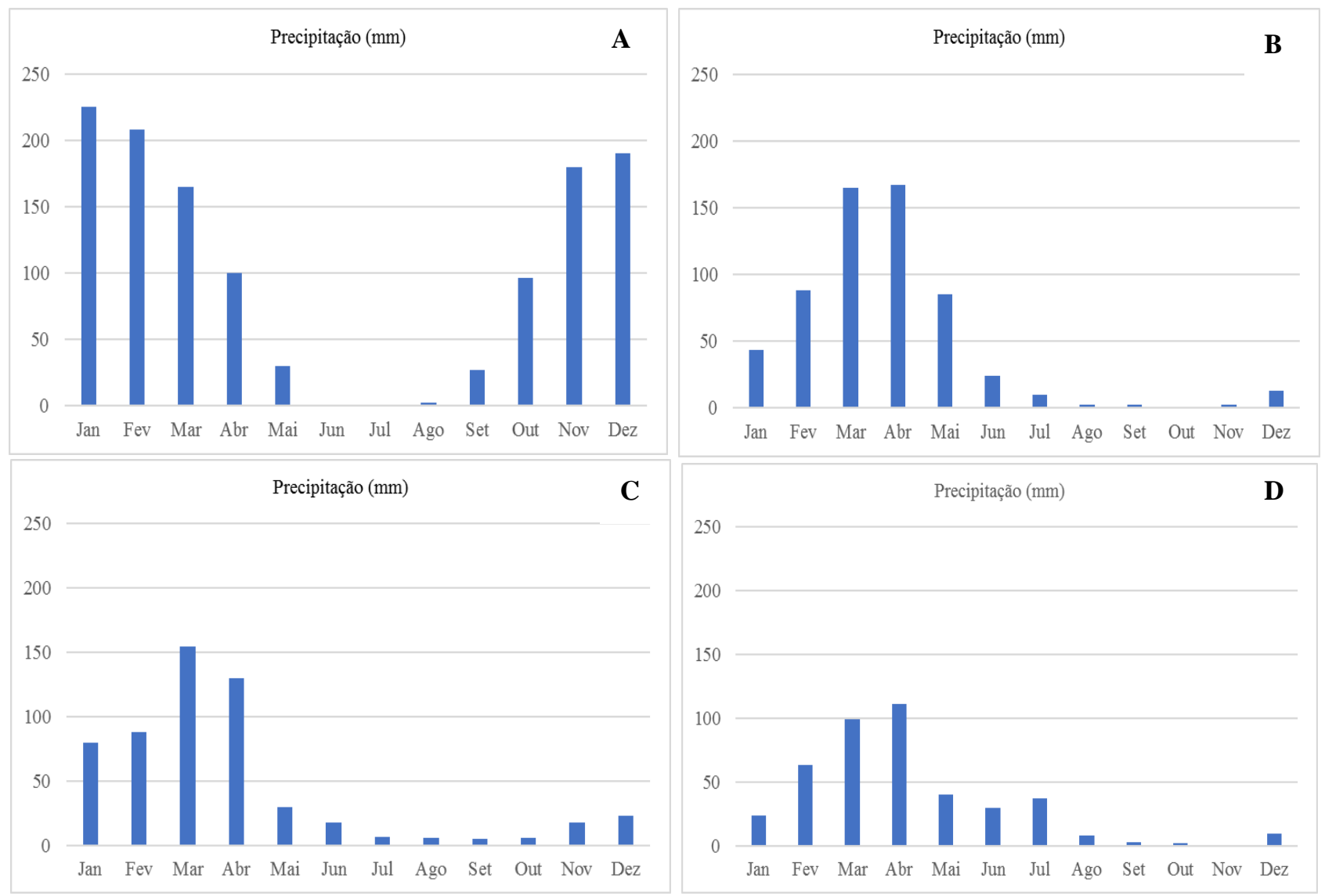

Figura 2 - Gráficos de pluviosidade média anual de Gilbués (A), Irauçuba (B), Cabrobó (C) e Seridó (D) Fonte: SUDENE E INMET

Por meio da análise dos quatro pluviogramas, verificou-se a dinâmica pluviométrica existente nos núcleos de desertificação. De um modo geral, pode-se constatar que existem semelhanças no regime e ritmo pluviométrico dos núcleos de Irauçuba, Cabrobó e Seridó. Entretanto, a dinâmica pluvial do núcleo de 
XVII Simpósio Brasileiro

de Geografia Fisica Aplicada

I Congresso Nacional

de Geografia Física
OS DESAFIOS DA GEOGRAFIA FÍSICA NA FRONTEIRA DO CONHECIMENTO

Instituto de Geociências - Unicamp

Campinas - SP

28 de Junho à 02 de Julho de 2017

Gilbués, difere dos demais, revelando duas estações climáticas bem definidas, que são marcadas por um longo período chuvoso durante o ano, opondo-se a outro mais seco.

Detalhando um pouco mais a descrição do quadro pluviométrico regional dos núcleos de desertificação do Braisl, convém mencionar outros aspectos, dentre os quais destacam-se:

a) o período de estiagem é mais prolongado nos núcleos de Irauçuba, Cabrobó e Seridó, do que em Gilbués, que tem predominância de um período chuvoso, se concentrando entre os meses de outubro a maio, sendo bem distribuído para uma ASD;

b) distribuição das chuvas é muito irregular, havendo concentração pluvial em alguns períodos, opondo-se a outros com precipitação rarefeita;

d) os períodos de menor pluviosidade ocorrem entre maio a setembro e os períodos de maior pluviosidade ocorre entre dezembro a abril;

e) o núcleo de Gilbués, apresenta quantidades pluviométricas bem superiores, do que os demais núcleos de desertificação em decorrência de se localizar em área com clima tropical subumido.

Neste contexto, algumas pesquisas (SALES, 1998; SILVA, 2014), apontam avaliações e críticas sobre o enquadramento de Gilbués como ASD. A classificação da região de Gilbués como Núcleo de Desertificação (VASCONCELOS SOBRINHO, 1978; FERREIRA et al., 1994) é contestada por Sales (1998), ao considerar a questão climática, onde os índices de aridez (IA) oscilam entre 0,86 e 0,96, permanecendo fora da zona adotada pela Convenção das Nações Unidas para o Combate à Desertificação.

Pela proposta da ONU as áreas preferencialmente sujeitas à desertificação teriam índices de aridez inferiores a 0,65, portanto, a região de Gilbués está fora das zonas suscetíveis ao fenômeno, por apresentar valores/índice de aridez bem acima do valor de referência do Programa das Nações Unidas para o Meio Ambiente (UNEP, 2007). Além do índice de aridez, existem outras diferenças climáticas, que distingue o núcleo de Gilbués com as demais áreas suscetíveis à desertificação no nordeste brasileiro, tais como: regime e distribuição pluviométrica, e abundância hídrica.

Silva (2014), ao desenvolver um estudo sobre a dinâmica pluviométrica de Gilbués, considera inadequado a utilização do termo desertificação para caracterizar os processos de degradação ambiental ocorridos na área em questão, devido às condições climáticas definirem as seguintes características: a) pluviosidade em torno de $1.200 \mathrm{~mm} / \mathrm{ano}$; b) ausência de aridez; c) carência de baixos índices pluviométricos; d) predomínio de um período chuvoso; e) abundância hídrica (rios perenes e aquíferos) (SILVA, 2014, p.173). 
Nesse sentido, há uma tendência mundial e, sobretudo no Brasil de restringir o conceito de desertificação aos processos de degradação do solo, relacionados às condições climáticas de regiões áridas e semiáridas. Todavia, o fato de Gilbués não se constituir como área em processo de desertificação, não significa desprezar os problemas que ali ocorrem e tampouco a urgência de ações de política de planejamento e controle para a recuperação das áreas degradadas.

Diante do panorama apresentado, a análise das condições climáticas e, especificamente, a caracterização do comportamento pluviométrico é de grande relevância para avaliar a suscetibilidade aos processos de desertificação, uma vez, que as condições climáticas, podem caracterizar e definir as ASD.

\section{Considerações finais}

Conforme os dados, a dinâmica pluviométrica dos núcleos de desertificação, se mostrou bem heterogênica, revelando por exemplo, semelhanças e diferenças e ainda uma significativa variação e amplitude pluviométrica entre as áreas analisadas. Desta maneira, verifica-se que o entendimento das características pluviométricas foi fundamental, para destacar o regime e a distribuição das chuvas em quatro localidades do nordeste brasileiro, três situadas em clima semiárido (Irauçuba-CE, Seridó-RN, e Cabrobó-PE), e uma localidade situada em tropical subúmido (Gilbués-PI).

De um modo geral, pode-se constatar que existem semelhanças no regime e ritmo pluviométrico dos núcleos de Irauçuba, Cabrobó e Seridó, que se localizam em clima semiárido. Entretanto, a dinâmica pluviométrica do núcleo de Gilbués, diferencia dos demais, revelando duas estações climáticas bem definidas, que são marcadas por um longo período chuvoso durante o ano, opondo-se a outro mais seco.

O núcleo de Gilbués, apresenta quantidades pluviométricas bem superiores $(1.200 \mathrm{~mm})$, do que os demais núcleos de desertificação, em decorrência de se localizar em área com clima tropical subumido. Já nas outras localidades, a pluviosidade varia entre $432 \mathrm{~mm}$ a $629 \mathrm{~mm}$. Assim, é notável perceber a discrepância referente a quantidade pluviométrica entre as áreas investigadas.

Acredita-se que a abordagem climática se apresenta relevante, para os estudos sobre desertificação/degradação dos solos, evidenciando, sobretudo as características pluviométricas, responsáveis pela gênese ou ampliação dos fenômenos de degradação ambiental que ocorrem, no território brasileiro.

Os resultados da dinâmica pluviométrica, encontrados neste trabalho, proporcionaram uma aplicação real da Climatologia Geográfica, no estudo do espaço, com possibilidade de oferecer suporte ao planejamento 
regional e local, não somente no tocante a aspectos pluviais, mas também no tocante a diferentes aspectos relacionados à análise ambiental.

\section{$5 \quad$ Bibliografia}

AB'SABER, A. N. Problemática da desertificação e da savanização no Brasil intertropical. Geomorfologia, 53. São Paulo: Instituto de Geografia. 1977.

BRASIL, GOVERNO DO. Desertificação - III Conferência das Partes da Convenção das Nações Unidas. Brasília: Ministério do Meio Ambiente/Prática, 1999. 23 p.

BRASIL, GOVERNO DO. Programa de ação nacional de combate à desertificação e mitigação dos efeitos da seca PAN-Brasil. Brasília, DF: Ministério do Meio Ambiente. Secretaria de Recursos Hídricos, 2004. 242p

CONTI, J. B. Desertificação nos trópicos. Proposta de metodologia de estudo aplicada ao Nordeste Brasileiro. 1995. Tese de Livre Docência apresentada na Faculdade de Filosofia, Letras e Ciências Humanas da USP, São Paulo,

FERREIRA, D. G.; MELO, H. P.; RODRIGUES NETO, F. R.; NASCIMENTO, P. J. S.; RODRIGUES, V. Avaliação do Quadro da Desertificação no Nordeste do Brasil: Diagnósticos e Perspectivas. Anais da Conferencia Nacional da Desertificação, Fortaleza. Brasília, Fundação Grupo Esquel Brasil, 1994. p. 7-55

NIMER, E. Subsídios ao Plano de Ação Mundial para Combater a Desertificação: Programa das Nações Unidas para o Meio Ambiente (PNUMA). Revista Brasileira de Geografia, Rio de Janeiro, v. 42, nº 3, 1980. p.: 612-637.

OLIVEIRA-GALVÃO, A. L. C. Reconhecimento da susceptibilidade ao desenvolvimento de processos de desertificação no nordeste brasileiro, a partir da integração de indicadores ambientais. Brasilia, UnB. Tese de Doutorado. 298p. 2001

SALES, M. C. L.. Estudo da degradação ambiental em Gilbués-PI: Reavaliando o "núcleo de desertificação". 1998. 181 f. Dissertação (Mestrado em Geografia) - Universidade de São Paulo, São Paulo, 1998

SILVA, I. A. S. Clima e arenização em Gilbués-Piauí: dinâmica das precipitações e a vulnerabilidade da paisagem aos eventos pluviais intensos. 2014. 185 f. Dissertação (Mestrado em Geografia) - Instituto de Estudos Socioambientais, Universidade Federal de Goiás, Goiânia, 2014.

SUERTEGARAY, D. M. A.; GUASSElli, L. A. e VERDUM, R. (Org.) Atlas da arenização - Sudoeste do Rio Grande do Sul. Porto Alegre/RS: Secretaria da Coordenação e Planejamento, 2001. 85 p

SUPERINTENDENCIA DE DESENVOLVIMENTO DO NORDESTE - SUDENE. Rede Hidroclimatológica do Nordeste. Disponível em http://pageserver-nt.sudene.gov.br/ixpress/pluviometria/plv/index.dml

UNEP - UNITED NATIONS ENVIRONMENT PROGRAMME.(2007). Section B: State-and-Trends of the Environment: 1987-2007. In: The fourth report in the Global Environment Outlook (GEO) series: 81-114.

VASCONCELOS SOBRINHO, J. Núcleos de desertificação no polígono das secas - nota prévia. In: ICB - UFPE, 1971, p. 69-73.

Metodologia para identificação de processos de desertificação: manual de indicadores. Recife: SUDENE, 1978. $18 \mathrm{p}$.

Núcleos de Desertificação no Polígono das Secas. In: VASCONCELOS SOBRINHO, J. de. Desertificação no Nordeste do Brasil. Recife: Ed. Universitária da UFPE. 2002

\section{$6 \quad$ Agradecimentos}

O autor agradece a Coordenação de Aperfeiçoamento de Pessoal de Nível Superior (CAPES) pela atual concessão de bolsa no Doutorado na Universidade Federal do Rio Grande do Sul. 